\title{
Clinical Case: Place of Cardiac Stimulation in Asymptomatic Significant Chronic Aortic Insufficiency Associated with Sinus Dysfunction
}

\author{
Adam Ahamat Ali1 ${ }^{1 *}$, Christophe Geyer ${ }^{3}$ \\ ${ }^{1}$ Renaissance Hospital of N'Djamena, N'Djamena, Chad \\ ${ }^{2}$ The Faculty of Human Health Sciences of N'Djamena, N'Djamena, Chad \\ ${ }^{3}$ Sainte Clotilde Clinical Cardiology Service, Reunion Island \\ Email: *aliadamahmat@hotmail.com, christophe.geyer993@orange.fr
}

How to cite this paper: Ali, A.A. and Geyer, C. (2019) Clinical Case: Place of Cardiac Stimulation in Asymptomatic Significant Chronic Aortic Insufficiency Associated with Sinus Dysfunction. World Journal of Cardiovascular Diseases, 9, 621-627.

https://doi.org/10.4236/wjcd.2019.99054

Received: July 30, 2019

Accepted: August 31, 2019

Published: September 3, 2019

Copyright $\odot 2019$ by author(s) and Scientific Research Publishing Inc. This work is licensed under the Creative Commons Attribution International License (CC BY 4.0).

http://creativecommons.org/licenses/by/4.0/

\begin{abstract}
The association between aortic insufficiency and sinus dysfunction is rare. We reported a case of significant chronic degenerative aortic insufficiency associated with sinus dysfunction. This was a 66-year-old patient on follow-up for asymptomatic chronic aortic insufficiency who was referred to us for a preoperative invasive hemodynamic assessment. The indication for surgery was based on the left ventricular dilation criteria. The echocardiography and cardiac catheterization showed a disappearance between the aortic insufficiency and the left ventricular repercussion. Upon discovery of the sinus bradycardia, the patient received a single chamber pacemaker set at a base rate of 70 seconds in AAIR at first and then the patient was measured remotely. At five months, cardiac pacing resulted in a significant reduction in the left ventricular diameter and volume on the echocardiography and magnetic resonance imaging; therefore surgery was postponed.
\end{abstract}

\section{Keywords}

Aortic Insufficiency, Sinus Dysfunction, Cardiac Stimulation, Sainte Clotilde Clinic, Reunion Island

\section{Introduction}

Dystrophic aortic insufficiency (AI) is common in western countries [1] [2], especially in the presence of aortic bicuspid disease. The association of a significant $\mathrm{AI}$ and sinus dysfunction is a rare entity. Bradycardia aggravates AI by increasing the duration of diastole, where the treatment of this bradycardia can delay the evolution of AI. We reported a case of significant chronic degenerative 
aortic insufficiency associated with sinus dysfunction.

\section{Observation}

Mr. B.J, 66 years old, was hospitalized in the cardiology department at Clinique Sainte Clotilde (Reunion Island) from 01/11/2016 to 07/11/2016 for preoperative invasive evaluation of a leaking aortic valve. His cardiovascular risk factors were: arterial hypertension treated with Aprovel $150 \mathrm{mg} /$ day and dyslipidemia with Lipanthyl $145 \mathrm{mg} /$ day. In August 2016, a polysomnography revealed a permanent bradycardia of less than 40 cycles/min; there was no sign of sleep apnea syndrome. The patient was followed for several years for a degenerative AI on bicuspid valve without dilatation of the aortic ring. He was asymptomatic when running and jogging three times a week (around 240 minutes). On the physical examination, he presented a good general condition. His clinical parameters were: body mass index at $24 \mathrm{~kg} / \mathrm{m}^{2}$, temperature at $36.5^{\circ} \mathrm{C}$, blood pressure at $135 / 65 \mathrm{~mm} \mathrm{Hg}$ and heart rate at 45 beats per minute. On cardiac auscultation the cardiac rhythm was regular with a diastolic murmur 2/6th along the sternum; there were signs of vascular hyperpulsatility with no signs of heart failure. Pulmonary auscultation was normal. The examination of the other apparatus was insignificant.

The biological blood tests were as follows: hemoglobinemia at $12.9 \mathrm{~g} / \mathrm{dl}$, prothrombin level at $90 \%, \mathrm{C}$ reactive protein at $4 \mathrm{mg} / \mathrm{l}$, glycaemia at $1.10 \mathrm{~g} / \mathrm{l}$, serum creatinine at $91 \mu \mathrm{mol} / \mathrm{l}$ with a clearance of $76 \mathrm{ml} / \mathrm{min} / \mathrm{m}^{2}$, normal hypersensitive troponin $<0.010 \mathrm{ng} / \mathrm{l}$, Brain Natriuretic Peptide (BNP) at $70 \mu \mathrm{g} / \mathrm{ml}$ (normal < 100), normal TSH at $3 \mathrm{mU} / \mathrm{l}$, total cholesterol at $1.44 \mathrm{~g} / \mathrm{ml}, \mathrm{HDL}$ at $0.37 \mathrm{~g} / \mathrm{l}, \mathrm{LDL}$ at $0.92 \mathrm{~g} / \mathrm{l}$, and triglycerides at $0.75 \mathrm{~g} / \mathrm{l}$.

The electrocardiogram showed a sinus bradycardia at 48 cycles per minute, a PR gap duration of $221 \mathrm{~ms}$, an incomplete left block, and nonspecific abnormalities of repolarization.

The 24-hour rhythmic Holter confirmed a polysomnography data with a permanent sinus bradycardia, a mean night time frequency of less than $40 / \mathrm{min}$ and mean day time frequency of around $50 / \mathrm{min}$. There was no prolonged pause or significant supraventricular or ventricular arrhythmia.

The stress test was conducted at $90 \%$ of the theoretical maximum frequency (MTF) which did not show a chronotropic deficit. The tension profile was normal.

In the transthoracic echocardiography (Figure 1) the left ventricle (LV) was hypertrophied (eccentric) and dilated with an end diastolic diameter (DTD) of $73.4 \mathrm{~mm}$ and a telencepolic diameter (SDR) of $47.6 \mathrm{~mm}\left(25.6 \mathrm{~mm} / \mathrm{m}^{2}\right)$, without a segmental kinetic disorder and a $60 \%$ systolic ejection fraction (EF). The filling pressures were normal. The left atrium was not dilated, there was an average AI on an anteroposterior bicuspid type 0. The ascending $\mathrm{AO}$ was not expanded measured at the Valsalva level at $42 \mathrm{~mm}$ and at the isthmus at $33 \mathrm{~mm}$. The right cavities were not dilated, however, the inferior vena cava was dilated. Systolic pulmonary arterial pressures were normal and the pericardium was dry. 


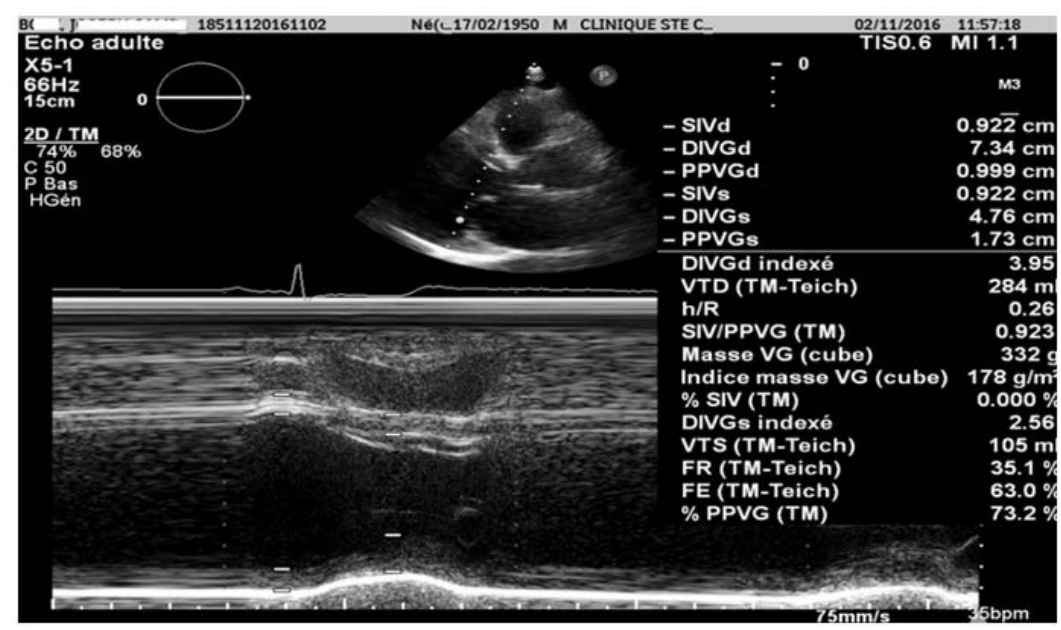

Figure 1. Cut-time motion (TM) on echocardiography showing LV and LVEF diameters.

On coronary angiography (Figure 2), the coronary arteries were atheromatous without significant focal lesions. On ventriculography, the left ventricle was dilated with an end-diastolic volume (EDV) of $149.5 \mathrm{ml} / \mathrm{m}^{2}$ and a telesystolic volume (TSV) of $53 \mathrm{ml} / \mathrm{m}^{2}$ with no segmental kinetic disturbance and a $64 \%$ left ventricular ejection fraction (LVEF). The sigmoidal aortogram revealed a medium to large AI.

The patient underwent implantation of a single-chamber pacemaker (AAI with placement of a Boston Accolade MRI SR compatible with thoracic magnetic resonance imaging (MRI) set at a base rate of 70 seconds in AAIR).

Five months later, the patient remained clinically stable. On echocardiography (Figure 3 ) and MRI (Figure 4) there was a coordinating and significant reduction in DTD $(<65 \mathrm{~mm})$, DTS $(<45 \mathrm{~mm})$ and LV volumes. The indication for surgery has been deferred.

On 05/07/2019 (32 months later), the patient was still asymptomatic with stable echocardiographic data (61 mm DTD and 60\% LVEF).

\section{Discussion}

The size of the leak depends on the size of the regurgitant orifice, the duration of the diastole, and the VG-aortic pressure gradient. In chronic IA, there is a decrease in aortic diastolic pressure, a vascular erethism responsible for peripheral signs of AI, an increase in residual LV volume resulting in LV dilatation by volumetric overload followed by eccentric LV hypertrophy, at least in the early phase [3]. The bradycardia prolongs the duration of the diastole, therefore the volume of the regurgitation is very important for the long diastole. The optimal heart rate is probably around 80 - 90 beats/minute [4]. A transthoracic echocardiography, possibly supplemented by transoesophageal examination, is the key diagnostic examination. It allows a reliable and reproducible quantification of regurgitation, the evaluation of its etiology, its mechanism, its left ventricular repercussion and the associated lesions, in particular the ascending aorta [5]-[11]. 


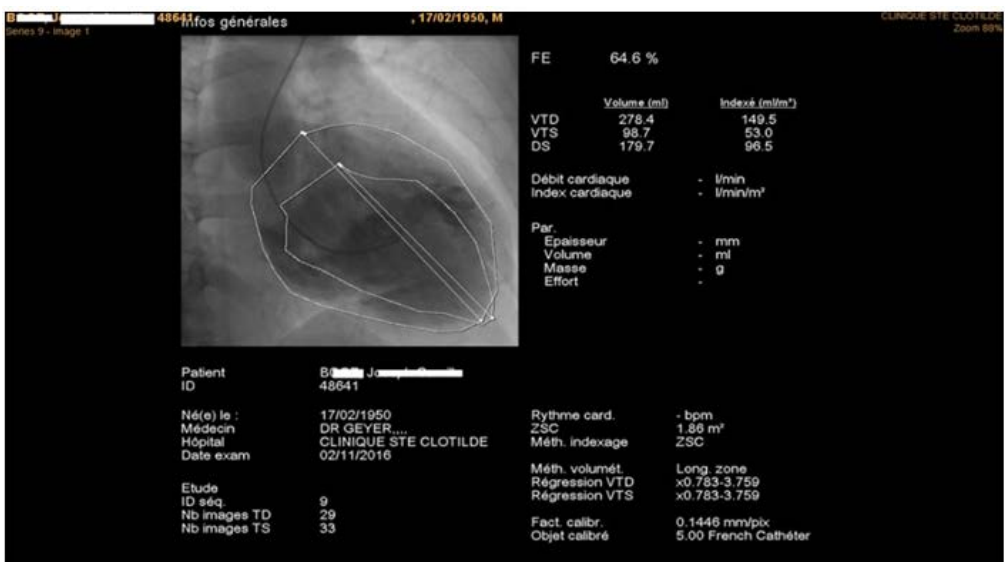

Figure 2. Left ventriculography showing LV and LVEF volumes.

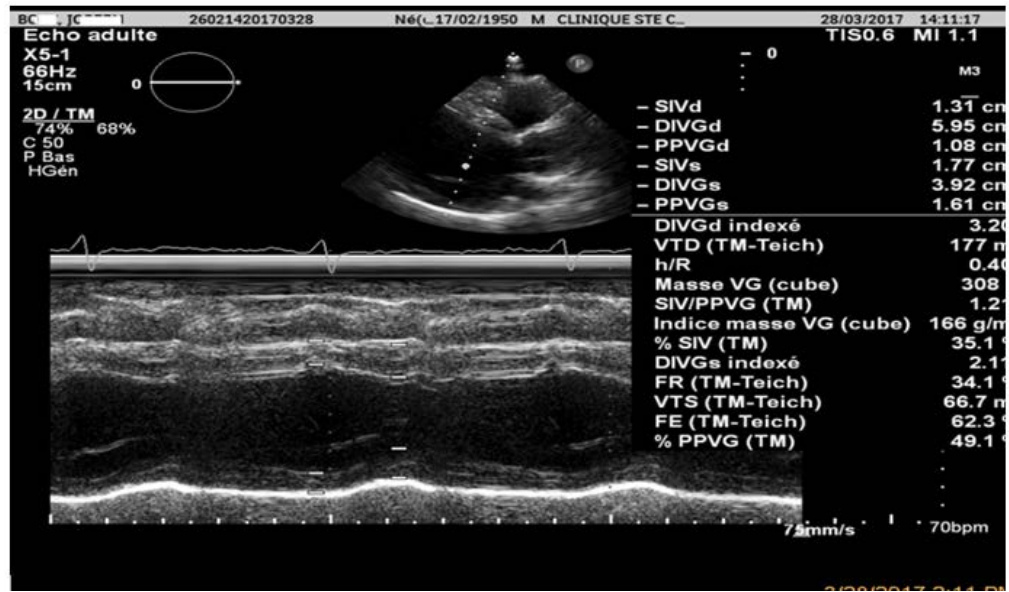

Figure 3. TM on echocardiography showing LV and LVEF diameters.

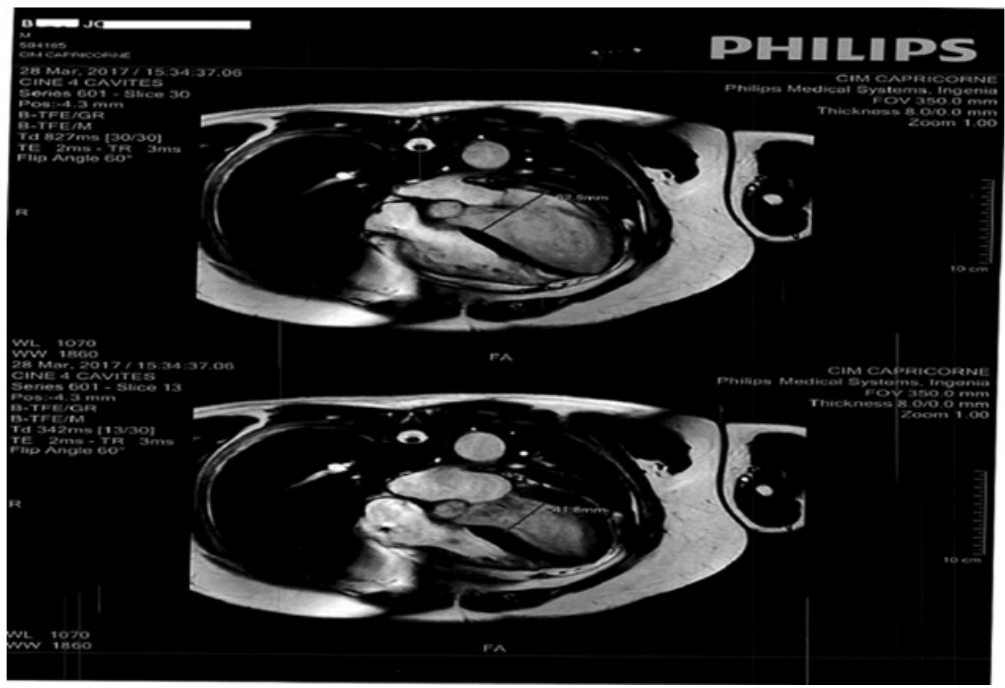

Figure 4. Cardiac MRI showing LV and LVEF diameters.

MRI is complementary to or even an alternative in the evaluation of valvulopathies in both anatomical imaging and functional imaging [7] [12] [13]. However, 
there is a considerable intra- and interobserver variability [14]. A long chronic AI can remain asymptomatic for long periods of time, possibly exceeding 10 years without impairment of systolic function, especially in rheumatic diseases. The risk of sudden death in the absence of symptoms is low ( $<0.2 \% /$ year) [15]. In asymptomatic AI, surgery is indicated [2] if there is impairment of the LVEF $(\leq 50)$ or significant dilatation of LV (DTD $>70 \mathrm{~mm}$ or DTSVG $>50 \mathrm{~mm}$ ) or $\left(>25 \mathrm{~mm} / \mathrm{m}^{2}\right)$. Surgery has a risk of serious complications, hence the interest of waiting for the ideal moment before carrying out the surgery. The optimal date of surgery in severe asymptomatic AI is determined by a follow-up and an existence of a significant LV resonance according to the criteria described above. The surgical treatment usually consists of a valve replacement by mechanical or biological prosthesis. Medical treatment is appropriate for delaying surgery in asymptomatic patients with large AI without surgical criteria or in symptomatic and/or LV dysfunction patients who can't be operated on due to major comorbidities. To our knowledge only one similar case has been published [16]. Our patient had a significant chronic AI, asymptomatic with an operative indication validated on echocardiographic criteria. According to current recommendations [2] [17], the surgical indication initially selected was based solely on VG dilatation criteria (normal LVEF, and normal BNP level). LV dilatation seemed disproportionate to the aortic insufficiency that wasn't major. The presence of permanent diurnal and especially nocturnal sinus bradycardia confirmed by the rhythmic holter of 24 hours suggested that LV dilatation was related to aortic leakage but was worsened by long diastole associated with bradycardia. The international recommendations and the level of evidence in the management of a severe asymptomatic AI left us with the opportunity to reflect and discuss the operative indications and to consider another therapeutic alternative without altering the patient's prognosis. The indication of stimulation in this case does not appear in the recommendations of cardiac pacemakers [18]. On the basis of physiopathology, our team has opted for an alternative stimulation by cardiac stimulation. The evolution was marked after five months by a clinical stability and a significant reduction of the diameters and volumes of the VG at the echocardiography and the MRI to exclude the patient of the surgical indication criteria. Thirty-two (32) months later the patient remained clinically stable and echocardiographically stable.

\section{Conclusion}

The association of AI and sinus dysfunction is not frequent. Significant sinus bradycardia should be sought in cases of severe asymptomatic AI while cardiac pacing helps to delay surgery.

\section{Conflicts of Interest}

The authors declare no conflicts of interest regarding the publication of this paper. 


\section{References}

[1] Iung, B., Baron, G., Butchart, E.G., Delahaye, F., Gohlke-Bärwolf, C., Levang, O.W., et al. (2003) A Prospective Survey of Patients with Valvular Heart Disease in Europe: The Euro Heart Survey on Valvular Heart Disease. European Heart Journal, 24, 1231-1243. https://doi.org/10.1016/S0195-668X(03)00201-X

[2] Baumgartner, H., Falk, V., Bax, J.J., et al. (2017) ESC/EACTS Guidelines for the Management of Valvular Heart Disease. European Heart Journal, 38, 2739-2791. http://www.escardio.org

[3] Carabello, B.A. and Crawford, F.A. (1997) Valvular Heart Disease. The New England Journal of Medicine, 337, 32-41. https://doi.org/10.1056/NEJM199707033370107

[4] Chassot, P.G. and Bettex, D. (2012) Précis d'anesthésie cardiaque, chapitre 11 Anesthésie et valvulopathies.

[5] Douglas, P.S. (2006) Improving Imaging. Our Professional Imperative. Journal of the American College of Cardiology, 48, 2152-2155. https://doi.org/10.1016/j.jacc.2006.04.107

[6] Société Française de Cardiologie, Abergel, E., Bernard, Y., Chauvel, C., Cohen, A., Cormier, B., et al. (2008) Mise à jour des recommandations de la Société française de cardiologie concernant les indications de l'échocardiographie doppler publiées en 1999. SFC, Paris.

[7] American College of Cardiology, American Heart Association, Bonow, R.O., Carabello, B.A., Chatterjee, K., de Leon, A.C., et al. (2008) Focused Update Incorporated into the ACC/AHA 2006 Guidelines for the Management of Patients with Valvular Heart Disease. Journal of the American College of Cardiology, 52, e1-e142. https://doi.org/10.1016/j.jacc.2008.05.007

[8] Iung, B., Baron, G., Butchart, E.G., Delahaye, F., Gohlke-Bärwolf, C., Levang, O.W. and Vahanian, A. (2003) A Prospective Survey of Patients with Valvular Heart Disease in Europe: The Euro Heart Survey on Valvular Heart Disease. European Heart Journal, 24, 1231-1243. https://doi.org/10.1016/s0195-668x(03)00201-x

[9] Tribouilloy, C.M., et al. (1998) Application of the Proximal Flow Convergence Method to Calculate the Effective Regurgitant Orifice Area in Aortic Regurgitation. Journal of the American College of Cardiology, 32, 1032-1039. https://doi.org/10.1016/s0735-1097(98)00356-8

[10] Roman, M.J., Rosen, S.E., Kramer-Fox, R. and Devereux, R.B. (1993) Prognostic Significance of the Pattern of Aortic Root Dilatation in the Marfan Syndrome. Journal of the American College of Cardiology, 22, 1470-1476. https://doi.org/10.1016/0735-1097(93)90559-J

[11] Karalis, O.G., Bansal, R.C., Hauck, A.J., et al. (1992) Transesophageal Echocardiographic Recognition of Subaortic Complications in Aortic Valve Endocarditis. Circulation, 86, 353-362. https://doi.org/10.1161/01.CIR.86.2.353

[12] Vahanian, A., et al. (2012) Guidelines on the Management of Valvular Heart Disease (Version 2012): The Joint Task Force on the Management of Valvular Heart Disease of the European Society of Cardiology (ESC) and the European Association for Cardio-Thoracic Surgery (EACTS). European Heart Journal, 33, 2451-2496.

[13] Vogel-Claussen, J., Pannu, H., Spevak, P.J., Fishman, E.K. and Bluemke, D.A. (2006) Cardiac Valve Assessment with MR Imaging and 64-Section Multi-Detector Row CT. Radiographics, 26, 1769-1784. https://doi.org/10.1148/rg.266065035

[14] Di Leo, G., D’Angelo, I.D., Alì, M., et al. (2017) Cardiac Magnetic Resonance Re- 
producibility Heart Valve Phase-Contrast Sequences Blood Flow. La Radiologia Medica, 122, 179. https://doi.org/10.1007/s11547-016-0706-6

[15] Tribouilloy, C., De Gevigney, G., Acar, C., Chassignolle, J.F., Cormier, B., Habib, G., Hanania, G., Iung, B., Leguerrier, A., Marchand, M., Michel, P.L., Obadia, J.F., Roudaut, R., Vahanian, A., Villemot, J.P. and Warembourg, H. (2005) Recommandations de la Sociétéfrançaise de cardiologieconcernantla prise en charge des valvulopathiesacquises et des dysfonctionsde prothèsevalvulaire. Archives des maladies du coeur et des vaisseaux, 98, 5-61.

[16] De la Rochelière, R., Gagnon, R.M., Beaudet, R. and Savard, D. (1990) Chronic Aortic Regurgitation: A Demonstration of the Effect of Bradycardia on Left Ventricular Function. Canadian Journal of Cardiology, 6, 24-26.

[17] Nishimura, R.A., Otto, C.M., Bono, R.W., et al. (2017) 2017 AHA/ACC Focused Update of the 2014 AHA/ACC Guideline for the Management of Patients with Valvular Heart Disease : A Report of the American College of Cardiology/American Heart Association Task Force on Clinical Practice Guidelines. Circulation, 135, e1159-e1195. http://circ.ahajournals.org/content/135/25/e1159

[18] Brignole, M., et al. (2013) ESC Guidelines on Cardiac Pacing and Cardiac Resynchronization Therapy: The Task Force on Cardiac Pacing and Resynchronization Therapy of the European Society of Cardiology (ESC). Developed in Collaboration with the European Heart Rhythm Association (EHRA). European Heart Journal, 34, 2281-2329.

\section{Abbreviation}

AI: aortic insufficiency;

LV: left ventricular;

MTF: theoretical maximum frequency;

TDD: telediastolic diameter;

TSD: systolic diameter;

EF: ejection fraction;

TDV: telediastolic volume;

TSV: telesystolic volume;

MRI: magnetic resonance imaging. 